\title{
Sexual health work in a playground: Lessons learnt from the evaluation of a small-scale sexual health project
}

\author{
Paula Baraitser, MBBS, MFFP, Senior Clinical Medical Officer; Frances Dolan, SRN, HV, FP Cert, Sexual Health Outreach Worker, \\ Department of Reproductive Health, Community Health South London NHS Trust, St Giles Hospital, London, UK; Rayah \\ Feldman, BA, DPhil, Senior Lecturer, Faculty of Humanities and Social Sciences, South Bank University, London, UK; Sarah \\ Cowley, BA, PhD, Professor of Community Practice Development, Florence Nightingale School of Nursing and Midwifery, Kings \\ College London, London, UK
}

Correspondence: Paula Baraitser, SCMO, Department of Reproductive Health, Community Health South London NHS Trust, St Giles Hospital, St Giles Road, Camberwell, London SE5 7RN, UK. Email: Paula.Baraitser@chsltr.sthames.nhs.uk

(Accepted 24 ${ }^{\text {th }}$ April 2001)

The Journal of Family Planning and Reproductive Health Care 2002: 28(1): 18-22

\begin{abstract}
Objective. To evaluate a sexual health outreach programme in an adventure playground.

Design. A qualitative approach to evaluation is appropriate for a sexual health project where outcomes are unpredictable, difficult to define in numerical terms and the small scale of the intervention means that an impact on indices such as teenage pregnancy rates is unlikely. The data collection techniques used were the outreach worker's diary, questionnaires and interviews with youth workers, and a focus group with young people.

Results. Work in young people's leisure space requires flexible working in disrupted environments and a responsive approach to diverse individual needs. The outreach worker successfully engaged boys and girls in sexual health discussions. As a result of the project, youth workers' confidence in discussing sexual health issues and ability to refer to the clinic increased.

Conclusion. Clinical staff providing a sexual health outreach service for young people offer a knowledge of sexual health and local clinical services and an opportunity to build positive relationships between clinics and local community organisations. The relationships help youth workers to raise sexual health issues with young people and to refer problems appropriately. Clinical staff doing outreach work may require additional skills to work in young people's leisure space, for example, the ability to negotiate the content of sessions and to tolerate disruption.

A qualitative approach to evaluation effectively documents a range of project outcomes, including those which were unforeseen and which could not have been documented through the collection of numerical data. It also provides a detailed description of the process of project implementation, which aids replication.
\end{abstract}

\section{Key message points}

- A qualitative approach to evaluation is appropriate for pilot sexual health projects where outcomes are unpredictable, difficult to define in numerical terms and there is unlikely to be an effect on indices such as teenage pregnancy rates.

- Sexual health outreach work requires flexible working in disrupted environments and a responsive approach to diverse individual needs.

- A positive relationship between organisations working with young people and local clinical services increases youth workers' confidence when discussing sexual health issues and the likelihood that they will respond to requests for sexual health advice.

\section{Introduction}

Rates of unintended pregnancy and abortion among teenagers in the UK are the highest in Western Europe. ${ }^{1} \mathrm{~A}$ number of pilot projects to reduce teenage pregnancy have been funded. Those planning services require evaluations of their effectiveness. This paper describes one such project and explores issues relevant to the evaluation of pilot interventions.

\section{The intervention evaluated}

The intervention evaluated is one element of a project supporting the use of mainstream contraceptive services by young people in Deptford, South London, an area with one of the highest under-16 pregnancy rates in the UK. ${ }^{2}$

Young people require easily accessible, friendly, confidential and non-judgemental services. ${ }^{3,4}$ A clinic fulfilling these criteria is now provided in Deptford. It offers an open access, confidential service that is open long hours and welcomes young people. The Deptford Sexual Health Project supports its use by developing a positive relationship between young people and their local clinic.

A key feature of this project is the relationship between the clinic and organisations working with young people locally. These links are developed and maintained by a sexual health outreach nurse who provides practical information on service access in a variety of community settings. The relationship between the clinic and one of these organisations, Deptford Adventure Playground, is described here.

The limitations of an experimental approach

Most health service evaluations take an experimental approach, that is they compare intervention and nonintervention groups, or the same group before and after intervention, using pre-set, numerical outcome measures such as teenage pregnancy rates. Experimental methodologies were first used in medicine to evaluate the effect of specific treatments (e.g. antihypertensives) on measurable indicators of health/disease (e.g. blood pressure). ${ }^{5}$ Since then they have been applied to the evaluation of complex interventions (e.g. sexual health service provision) which are not easily controlled and have diverse outcomes. There are a number of limitations to this transfer of methodologies: $:^{5-7}$

- The nature of innovative projects means that their outcomes cannot be predicted and are therefore difficult to define at the start of the project. 
- Many outcomes cannot be documented in numerical terms, e.g. teamwork with partner agencies, a key feature of this project.

- Small projects are unlikely to have a significant effect on occurrences such as teenage pregnancy, which are uncommon at local level.

- Experimental evaluations do not document the process of project implementation, though this information facilitates replication and improvement. ${ }^{8}$

\section{The alternative}

An alternative, developmental approach ${ }^{5}$ to the evaluation of the Deptford Sexual Health Project was taken. This was naturalistic in that there was no attempt to control the intervention. A variety of qualitative methodologies were used to provide an account of the process of project implementation. Outcomes were not pre-set, but were identified by clients, staff and partner agencies during the course of the project. Methodologies were chosen to facilitate the documentation of complex outcomes. Different views of the project were compared, and their context documented wherever possible. The intention was to test the feasibility of this approach to the evaluation of sexual health services, and its ability to generate information relevant to decisions about project replication.

\section{The researchers}

Both researchers work in the Department of Reproductive Health Care, Community Health South London NHS Trust, and are involved in the planning and implementation of the project. PB is the principal researcher and FD the outreach nurse whose diary and records from questionnaires and focus groups provide the raw data for the project. Like all researchers, they bring their own values to the research and their findings should be considered with reference to their relationship to the project. Involved researchers offer the advantage of a detailed knowledge of the project and close relationships with those studied.

\section{Method}

The following data collection strategies were used:

1. The sexual health outreach nurse kept a dictaphone diary describing her work. This diary was fully transcribed.

2. The outreach nurse administered questionnaires testing the knowledge of local contraceptive services to the three adventure playground youth workers at the beginning of the project and 6 months later.

3. The outreach nurse conducted a focus group with three male and four female adventure playground users at the end of the intervention. The sample was a pragmatic one of those who were present and willing to take part. The questions aimed to generate a discussion of local sources of information about general and sexual health as a way of indirectly assessing the impact of the project on playground users' knowledge of these. The focus group content was recorded on flip chart paper during the session. It was observed by an academic with no relation to the project, who produced a written report. It was tape recorded and fully transcribed.

4. The principal researcher met with the senior youth worker to discuss the project at the end of the 9-month period. Her impressions were recorded in note form.

Analysis

An inductive approach to analysis was used.
1. The transcripts of the sexual health outreach nurse's diary and the focus group were jointly coded by the outreach nurse and the principal researcher. Themes were identified as the data were collected, and subsequent analysis focused on testing the validity of organising the data in this way.

2. Data from interviews with staff were collated according to topic and matched with relevant diary entries.

3. The external academic's focus group report, the flip chart summaries, the relevant diary entries and the focus group transcripts were compared.

4. Confirmatory tactics, such as triangulation between the different data sources, looking for negative cases and checking results with respondents, were used to check the accuracy of the conclusions.

\section{Results}

Deptford Adventure Playground: the place

The Deptford Adventure Playground is open for those aged 5-18 years. The outside space has a football and basketball pitch and an adventure playground. The indoor space has a table tennis and pool table and an art room. The outreach nurse's first impressions were:

"It was quite bleak in some ways. The outside was very
good because it is a huge sort of really good play area
for kids and felt quite secure and almost private and
really nice for them to be running around after school
and climbing and swinging. Quite exciting sort of play
area, autumn leaves hiding walkways and all that nice
sort of stuff... But the inside area was really scruffy. I
mean there was nowhere nice for the kids to sit, but
there was pool tables and football." (Diary 21/9/99)

Deptford Adventure Playground: the work

The sexual health outreach nurse completed 18 sessions of 1-2 hours, during which she had about 70 discussions with playground users. More than half of these were with boys. Discussions were informal, and their content negotiated. They were initiated by offering clinic leaflets or the opportunity to talk, 'hanging around' when playground users were engaged in activities such as art work or setting up a table with information leaflets, condoms, etc. Sexual health promotion posters were hung on the walls and remained there between sessions. The topics covered were the location, times and confidentiality policy of the local clinic, contraception, sexually transmitted infection, puberty, menstruation, cervical screening and testicular self-examination.

\section{Sexual health work in a 'playground'}

Deptford Adventure Playground functions both as a playground and as a social space for teenagers, and it therefore attracts users from a wide age range (5-17 years). The outreach nurse responded to the information needs of users from the age of eight upwards, but worked mainly with those aged 13-16. She found the provision of ageappropriate material to younger users rewarding, as they were less embarrassed and keener to learn than older users.

"I think the most interesting thing was that there were three year six girls who were really, really interested. They'd had sex education at primary school and they were just like fascinated and asking intelligent questions, openly without embarrassment..." (Diary $15 / 2 / 00)$ 
Among older playground users there was a lot of variation in the sexual health information needs, even of users of a similar age. Working individually or in small groups, the sexual health nurse was able to tailor her discussions to their requirements.

"Then I talked to two white girls from year 11 ... she was quite knowledgeable, the first girl, ... she knew about emergency contraception ... quite well informed, sort of together sort of girl. Then I spoke to two girls also just 16 ... and neither of knew anything about contraception." (Diary 4/10/99)

Sexual health work in 'their' space

In contrast to sex education in clinics or schools, the work in Deptford Adventure Playground was conducted in the users' leisure space and the outreach nurse was conscious of her status as a visitor. She had to be proactive about engaging young people, but at the same time ensure that she was not intrusive.

"Its just a very fine balance between been putting kids on the spot and being too obtrusive, and not doing any work at all, and I had to really draw them in to come in. And trusting you to sit and really chat about stuff they really do need." (Diary 21/9/99)

The playground's status as 'their' space meant that the behaviour of participants was less controlled than in school or clinic environments and some sessions were very disrupted, with young people running in and out of the room shouting and screaming or throwing leaflets or condoms around. Despite the disruption, the outreach worker was able to engage playground users. The external observer commented after the focus group at the end of the intervention:

\begin{abstract}
"Despite shouting and screaming, the young people did not leave the room but engaged with Fran (the outreach nurse) and undertook planned activities. Although their attention span was short, they interacted and were not passive."
\end{abstract}

The young people's engagement and their short attention span is consistently referred to in the outreach worker's diary:

\begin{abstract}
"I think they were taking in bits and pieces, but again it's very much on their terms and if they don't want to listen, they won't listen. So you have to kind of slip things in and engage them just a little bit, and then listen to their stuff and then engage them just a little bit more." (Diary 2/11/99)
\end{abstract}

Working on their terms also generated situations where participants did become engaged in discussion. This often occurred where sexual health topics could be related to existing discussions, as described below:

\footnotetext{
"S (youth worker) was playing cards with about four girls and looked really sort of groupy thing there ...Um, so I sort of hang around the card game for a while, the very appropriate card game they were playing was dirty slag. ... So in the end I got chatting to them and ended up having about an hour's long chat with about four or five girls." (Diary 2/11/99)
}

Sexual health work in a potentially sexualised environment An issue related to working in 'their' space was the impact of the sexual aspects of relationships between playground users on the work. Sometimes existing conversations about sex provided a forum for discussing sexual health issues:

\begin{abstract}
"Had a vivid description of $K$ 's dream, really vivid. She was dreaming about $D$ the night before, having sex with $D$, so that was a lot of hilarity. A lot of hilarity. It was really funny and it was very easy going between all of us, so that really created the atmosphere to talk about other things (sexual health issues) as well." (Diary 2/11/99)
\end{abstract}

The outreach nurse carefully negotiated the content of discussions so that potentially offensive or inappropriate material (for example that which is homophobic or misogynist) was responded to appropriately. Less experienced workers were not always able to do this, and during one session led by a trainee youth worker the playground users became:

\begin{abstract}
"Very challenging, very provocative and very sexual towards her (the trainee youth worker), using her as an excuse to come out with some quite nasty stuff." (Diary $14 / 3 / 00)$
\end{abstract}

Although the trainee youth worker felt she had been able to challenge their views, the permanent youth worker said:

"She didn't like it and it was all pornographic stuff and she wasn't happy about it." (reported speech of youth worker in Diary $7 / 3 / 00$ )

Two youth workers suggested that the regular presence of the sexual health nurse changed the atmosphere at the playground as users became more used to discussing sexual health topics and less embarrassed about acknowledging sexual health problems.

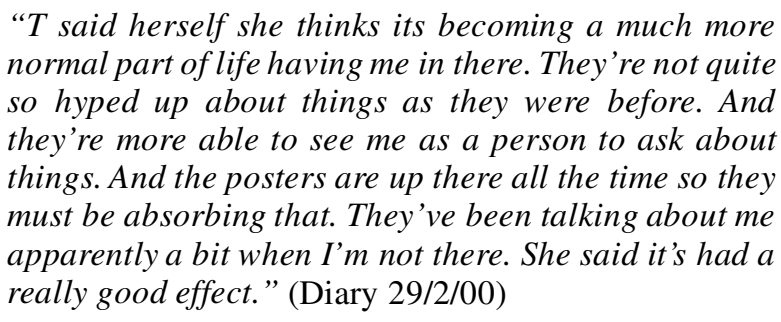

Sexual health work with youth workers

The youth workers were very positive about the project. The first questionnaires demonstrated their limited knowledge of local family planning services. Although they all knew that a family planning clinic existed at the local health centre, none had specific knowledge about clinic times or confidentiality policy, and none had personal links with clinic staff. Only the senior youth worker had advised young people on specific sexual health problems. The younger youth workers had either never advised young people on sexual health, or had done so in a general way only, for example, recommending that they attend a family planning clinic without details of how to do this or further discussion of the problem. After the intervention all youth workers reported having much more specific knowledge of how to access contraceptive services, the clinic confidentiality policy and the time limit for emergency contraception. The youth workers reported that their 
increased knowledge resulted in greater confidence when discussing sexual health.

\begin{abstract}
"So I had a very good chat with $M$ to start with. And also got a lot of feedback about how valuable he thought the project was, which was very nice to hear. And how it's moved him on to talk to people more. Clarified a lot of issues for him and firmed up details. Said he's now, enabled him to say things more to people.... And then I had a long chat with T.... Basically she seems to have moved on and she can talk more to people now. She's actually much more able to talk to people. Whereas before she might have said go and see your mum, she now actually says, she wouldn't actually talk about details, but she is able to say go down to the clinic and she knows exactly where it is can give them a leaflet, look at the poster." (Diary 29/2/00)
\end{abstract}

The senior youth workers' positive views of the project were reiterated in the meeting with the principal researcher at the end of the project, and were confirmed by their commitment to ensuring that clinic publicity was prominently displayed. As a result of the project two youth workers visited the clinic to see it for themselves and during the course of the project at least one young person was referred by a youth worker for immediate contraceptive advice.

\section{Playground users assessment of the project}

The focus group demonstrated participants' knowledge of local family planning services and emergency contraception.

\begin{abstract}
"The knowledge of the group about where the family planning clinic was located was apparent. Although they didn't know any precise details about the opening hours, they did have an idea about where to go for information about sexual health and family planning. They knew about emergency services and the morning after pill. The amount of knowledge they had was significant." (External observer's report on the focus group 06/06/00)
\end{abstract}

However, on informal direct questioning during the course of the project playground users were reluctant to acknowledge that the project had been useful to their peers.

ON: "So what do you think about me coming to the adventure playground, do you think it's helping people know more stuff or do you think it's just all stupid?"

U: "Not really because everyone knows what sex is all about, like everybody knows about that kind of thing." ON: "Do you think everybody knows everything?"

U: "Not everything, but most things."

In addition to the one young person who was referred to the clinic by a youth worker, three others are known to have visited the clinic as a result of the sexual health outreach worker's presence.

\section{Discussion}

The description of the outreach work above should be considered in relation to the worker's previous experience in clinics and schools. The emphasis on the informal, responsive and disrupted nature of the work in the playground implies a contrast with more controlled environments. The acknowledgement of this contrast is important. Clinical staff from sexual health services are often invited to provide sex education in community organisations because of their knowledge of sexual health and local services, but with little consideration of their ability to work in non-clinical environments. This study indicates that this transition is possible, but that staff should be prepared to negotiate the content of, and tolerate disruption during, sessions.

The requirement to negotiate arises from siting the work in young people's space. Another aspect of this is the acknowledgement that it is an environment in which sex is a common topic of conversation and where there is ongoing negotiation of sexual relationships. This had a positive impact on the work in that spontaneous discussions about sex could be used as the basis for discussions about sexual health. It also had a negative impact in that playground users were fearful of exposing their lack of knowledge or sexual experience, and this sometimes inhibited discussion. In addition it inhibited their willingness to admit that the project had increased their knowledge, since many would not admit that they had lacked knowledge in the first place. This is consistent with other work, which shows that young people's fear of the judgement of adults and the ridicule of their peers inhibits them from talking about sexual health. ${ }^{7}$

The responsive nature of the outreach worker's approach meant that she could meet the diverse needs of young people of different ages and with different levels of knowledge. Respect for this diversity is an important element of sex education programmes ${ }^{3}$ and is difficult in school settings where it is assumed that young people of a similar age have similar sex education needs. The project was unusual in that it was successful in engaging boys, and this model may be an effective way of encouraging young men to use family planning services.

Unlike the young people, the youth workers did acknowledge that the project had improved their knowledge of sexual health and sexual health services. Their technical knowledge, for example, about emergency contraception had increased, and so had their understanding of the ethos of local services. Having formed a positive relationship with a member of clinic staff and visited the clinic, the youth workers reported that they were more likely to refer young people there. Whereas technical information and even the location and hours of local services could have been gained from a training course, the development of a relationship between playground and clinic could not. It seems that the latter is an essential part of encouraging referrals from youth workers.

The study piloted a qualitative evaluation methodology as a means of generating information relevant to decisions about continued project funding or replication. It shows that this approach can provide a detailed description of the process of implementation and therefore serve as an aid to project replication. In addition the methodology has documented a range of project outcomes, including those which were unforeseen and could not have been documented through the collection of numerical data. Examples of such outcomes are the changes in atmosphere at the adventure playground in relation to the discussion of sexual health issues, the positive relationship that developed between the youth workers and the outreach nurse, and the youth workers increased confidence in discussing sexual health with young people. Although many of these outcomes were initially identified by the outreach worker herself, the collation of multiple data sources (e.g. youth workers, views and observation by the principal researcher) allowed information to be cross-checked and confirmed. What this methodology could not generate was numerical data on the influence of the project on patterns 
of sexual behaviour or sexual health service use. For confidentiality reasons this type of data is difficult to collect by any method. Although it is known that some young people visited the clinic as a result of the project, this information is not complete. Further research is planned to assess the ability of the qualitative data generated to influence the decisions of those planning future service provision.

\section{Statements on funding and competing interests}

Funding. This project was funded by 'Bridging the Gap' a partnership of local people, statutory and voluntary organisations, the local Council and business community in Deptford, South East London, a recipient of Single Regeneration Budget Funding. We are grateful for their support.
Competing interests. See statement in the paper on authors' relationship with the project.

Social Exclusion Unit Report on Teenage Pregnancy. London: HMSO, 1999. The Health of Londoners: Contraceptive and Abortion Services in London. London: East London and the City Health Authority, 1997.

Aggleton P, Oliver C, Rivers K. Reducing the rate of teenage conceptions: the implications of research into young people, sex, sexuality and relationships. London: Health Education Authority, 1998

Egg Research and Consultancy. 'Someone with a smile would be your best bet'; what young people want from sex advice services. London: Brook Advisory Centres, 1998.

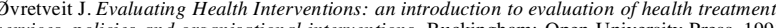
. Social Sciences in Health 1998; 4: 90-103.

Harris J, Hutchinson A, Sellers T, et al. User oriented strategies for preventing unwanted pregnancy in adolescents. Final Report NHS Research and Development Programme. Hull: The University of Hull, 1999

Patton M. Qualitative evaluation and research methods. Newbury Park: Sage, 1990. 